\title{
THE SHOULDER IN KUUTTLIPLE EPIPHYSEAL DYSPLASIA
}

ROLAND R. INGRAM

From the Victoria Infirmary, Glasgow

\begin{abstract}
One hundred shoulders were assessed in $\mathbf{5 0}$ patients with multiple epiphyseal dysplasia, of which onethird were found to have bilateral symptoms. Two distinct clinical and radiological groups emerged. Those with minor epiphyseal abnormalities developed painful osteoarthritis in middle age, but retained shoulder movement until the secondary changes were advanced. Those with 'hatchet head' shoulders likewise became painful in the fifth and sixth decades but had minimal glenohumeral movement from an early stage.
\end{abstract}

Multiple epiphyseal dysplasia is an inherited disorder, predominantly autosomal dominant, resulting in abnormal formation of limb epiphyses. Affected individuals may have a degree of short-limbed dwarfism, short stubby digits and stiff or painful joints (Fairbank 1947). Presentation is most common around the age of seven years with hip or knee symptoms. It is well recognised that some patients are prone to develop degenerative joint disease, particularly of the hip and knee, at an early age. There is little information, however, concerning the incidence and severity of upper limb problems. The aim of this study was to define the extent of the clinical problem in the shoulder joint and to classify the radiological appearances.

\section{PATIENTS AND METHODS}

Fifty patients with multiple epiphyseal dysplasia were examined over a two-year period at skeletal dysplasia clinics in the following centres: St Thomas's Hospital, London; Harlow Wood Orthopaedic Hospital, Mansfield; Robert Jones \& Agnes Hunt Orthopaedic Hospital, Oswestry; Princess Margaret Rose Hospital, Edinburgh; and the Victoria Infirmary, Glasgow.

There were 27 males and 23 females aged between four and 67 years (mean 30). A general history and examination of the musculoskeletal system was noted. The clinical method of functional assessment of the shoulder described by Constant and Murley (1987) was used to evaluate 100 shoulders; this method combines a number of subjective and objective factors in an overall 100-point scoring system.

R. R. Ingram, FRCS, Senior Registrar

Department of Orthopaedic Surgery, Royal Infirmary, Glasgow G4 OSF, Scotland.

(C) 1991 British Editorial Society of Bone and Joint Surgery 0301-620X/91/2089 $\$ 2.00$

J Bone Joint Surg [Br] 1991; 73-B :277-9.
Table I. Clinical grading of shoulders

\begin{tabular}{lll}
\hline Grade & Score & $\begin{array}{l}\text { Number of } \\
\text { shoulders }\end{array}$ \\
\hline Normal & $>80$ & 69 \\
Mild & 60 to 80 & 17 \\
Moderate & 40 to 60 & 10 \\
Severe & $<40$ & 4 \\
\hline
\end{tabular}

Radiology was kept to a minimum to avoid overexposure in patients with multiple joint problems. Only those with shoulder symptoms or abnormalities on clinical examination had radiographs taken; the films were confined to anteroposterior views in the neutral position and with the arm in maximum abduction. The amount of glenohumeral abduction was measured by the difference in the angle between the joint surface of the glenoid and the long axis of the humeral shaft, in neutral and in maximum abduction. Patients with clinically normal asymptomatic shoulders were not radiographed but any previous shoulder and chest films were examined.

\section{FINDINGS}

Clinical. There were 31 symptomatic shoulders in 16 patients; their symptoms were graded according to severity (Table I). There was no significant difference between the sexes. Shoulders tended to be affected symmetrically; only one patient had unilateral symptoms and in only four was there a difference of 10 points or more between left and right shoulder scores.

Eight shoulders had low scores because of restricted joint movement only. These tended to be in younger patients, with a mean age of 26.5 years (range 15 to 34 ). Twenty-three shoulders in 12 patients were painful, nine in the mild group and 14 in the moderate or severe group. 
The mean age for patients with painful shoulders was 51 years (range 34 to 67). One patient had had bilateral shoulder arthroplasty and another is awaiting shoulder replacement.

All the patients with symptomatic shoulders were 'severe' cases of multiple epiphyseal dysplasia with typical stubby digits, short-limbed dwarfism and serious joint abnormalities in the lower limbs.

Radiological. Radiographs were taken of 32 symptomatic shoulders, and 22 of the asymptomatic shoulders had previous films available; 23 asymptomatic patients had no shoulder radiographs.

The radiographs were classified into four groups (Table II). The 'normal' group consisted of asymptomatic patients with normal radiological shoulder joints. The 'minor epiphyseal abnormality' group also consisted of asymptomatic patients, though they were generally younger. The radiographs demonstrated minor changes in the humeral heads, such as slight flattening of a small section of the proximal humeral epiphyses (Fig. 1). The glenoid fossae were normal and there was no radiological evidence of arthritis.

The 'osteoarthritic' group were generally older and were all symptomatic. Whilst they had radiological changes of osteoarthritis (Fig. 2a), there was no gross distortion of bony anatomy. The humeral heads appeared basically spherical and congruent. The glenoid fossae were not grossly deficient. The glenohumeral component of abduction was measured from radiographs in 10 shoulders in this group. The mean range of motion was $32^{\circ}$ (range $0^{\circ}$ to $60^{\circ}$, Fig. 2b).

The 'hatchet head' group came from a wide age range and all had shoulder symptoms. The radiographs showed typical changes in the proximal humeral epiphysis which was grossly deformed resulting in the hatchet shape. There was commonly a broadening of the metaphysis and a slight bowing of the proximal diaphysis. The glenoid fossa was poorly formed, its inferior aspect merging into the lateral border of the blade of the scapula (Fig. 3a). The term 'congruous incongruity' may be appropriate to this particular shoulder deformity. Eight shoulders in the four youngest patients in this group were pain free but had marked restriction of movement as a consequence of the deformity. The mean glenohumeral component of abduction measured in 16 shoulders was $7^{\circ}$ (range $0^{\circ}$ to $15^{\circ}$ ).

\section{DISCUSSION}

It has long been recognised that patients with multiple epiphyseal dysplasia are prone to develop degenerative changes in the large joints of the lower limbs at a relatively young age. Whilst it has been appreciated that similar changes may occur in the upper limb (WynneDavies, Hall and Apley 1985), and the shoulder joint in particular, there is little information as to the extent or severity of the problem.
Table II. Radiographic classification

\begin{tabular}{lllc}
\hline & $\begin{array}{l}\text { Number of } \\
\text { shoulders }\end{array}$ & $\begin{array}{l}\text { Mean age } \\
(\mathbf{y r})\end{array}$ & $\begin{array}{l}\text { Age range } \\
(\mathbf{y r})\end{array}$ \\
\hline Normal & 10 & 27.4 & 4 to 41 \\
$\begin{array}{l}\text { Minor epiphyseal } \\
\text { abnormalities }\end{array}$ & 12 & 17.3 & 14 to 25 \\
$\begin{array}{l}\text { Osteoarthritis } \\
\text { Hatchet heads }\end{array}$ & 12 & 54.8 & 40 to 67 \\
\hline
\end{tabular}

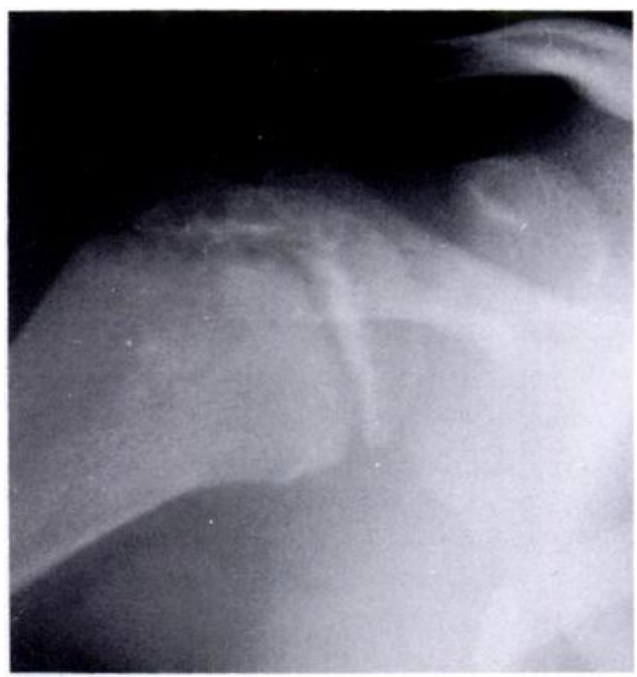

Fig. 1

Minor epiphyseal abnormality - there is slight irregularity of the humeral head.

This series demonstrates that approximately onethird of patients with multiple epiphyseal dysplasia will have shoulder symptoms; as in the lower limbs, the shoulders are affected symmetrically.

It seems clear that there are two types of shoulder abnormality, each with its own distinct natural history.

Minor epiphyseal abnormality group. The patients with minor epiphyseal abnormalities (mean age 17.3 years) may well go on to develop the changes described as osteoarthritis, which were seen at a mean age of 54.8 years. Both varieties should probably be grouped together; they are certainly distinct from the hatchet-head group in that they retain a basically spherical and congruent humeral head and a well formed glenoid fossa.

These combined radiological groups (12 patients with 24 shoulders) constitute approximately half the shoulder abnormalities in multiple epiphyseal dysplasia. They remain asymptomatic until middle age when a large proportion becomes painful. However, they retain a good range of movement, in particular glenohumeral abduction, even into middle age. Only when the effects of the secondary arthritis supervene does the joint stiffen. 
Figure 2a - Osteoarthritic shoulder joint with loss of joint space, osteophytes and sclerosis. The humeral head remains roughly spherical and the glenoid is properly formed. Figure $2 b$ - Despite degenerative changes this shoulder retains a reasonable range of glenohumeral movement in abduction.

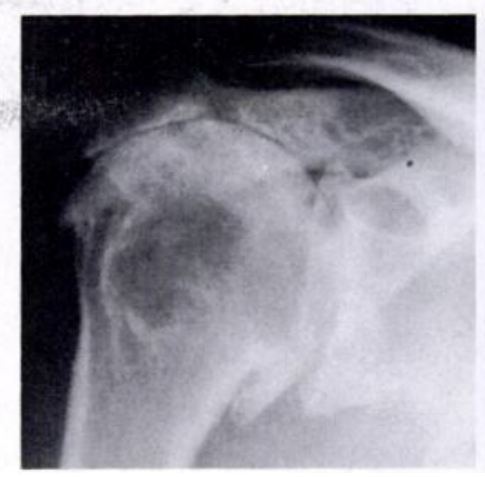

Fig. 2a

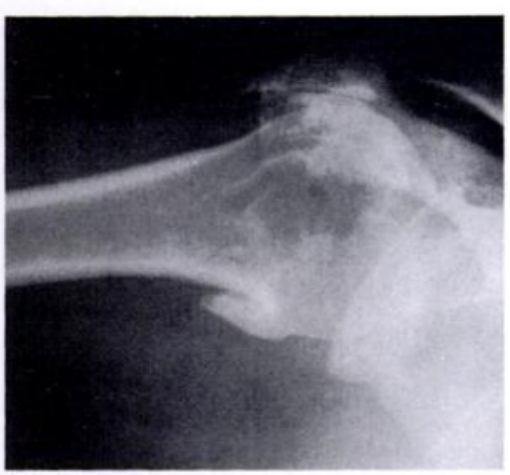

Fig. 2b

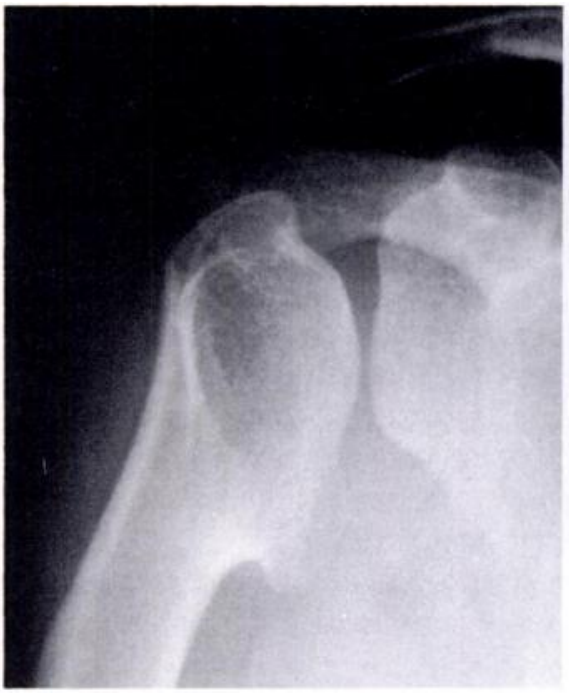

Fig. 3a

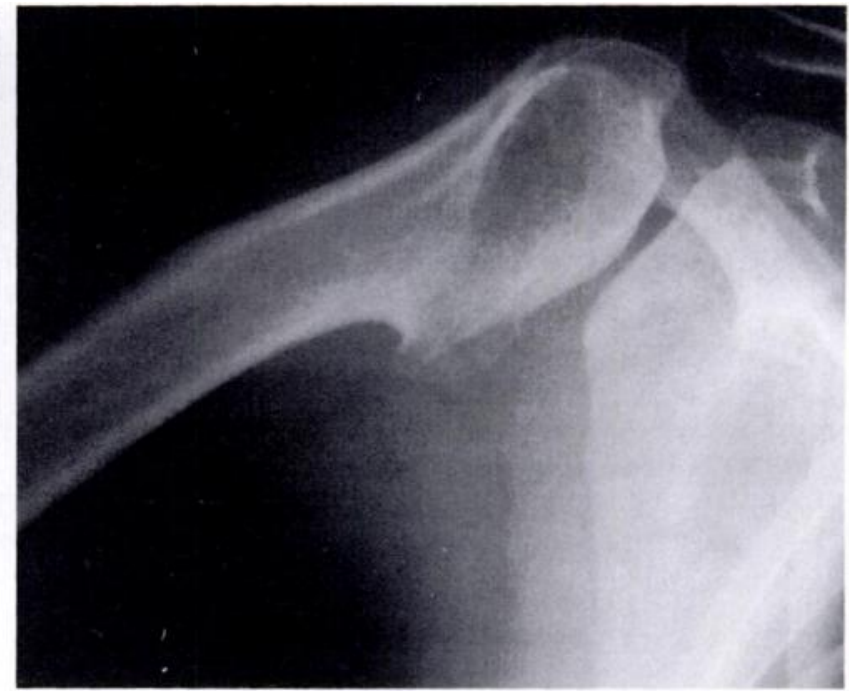

Fig. 3b

Figure 3a - Hatchet head shoulder with malformed humeral head, broad metaphysis and slight bowing of the proximal shaft. The glenoid is poorly developed. Figure $3 \mathrm{~b}-$ Abduction is severely restricted by an almost complete absence of glenohumeral movement.

Hatchet-head group. These shoulders have clinical and radiological abnormalities from an early stage. Even though pain free in teenagers and young adults, glenohumeral movement is severely restricted. These patients commonly appreciated that their shoulders were 'stiff', though generally they had little disability because their scapulothoracic movement was adequate. However, with advancing years these shoulders, like the 'minor epiphyseal abnormality' group, became painful. There were 10 patients with 20 shoulders in this group.

Conclusions. Although hip and knee symptoms predominate in multiple epiphyseal dysplasia there is a significant incidence of shoulder problems, particularly by the fifth and sixth decades. The two radiological groups of shoulder abnormality differ clinically in that the hatchethead group lack significant glenohumeral movement from an early age. Shoulder arthroplasty may have an increasing role in the management of these patients.

I would like to thank Dr R. Wynne-Davies, Messrs J. F. Crossan, G. A. Evans, G. C. W. Baker, C. J. Howell, M. A. Smith, J. N. A. Gibson and Professor S. P. F. Hughes for allowing me to study their patients. I also thank the Skeletal Dysplasia Group which provided the background organisation and travel costs necessary for this study.

No benefits in any form have been received or will be received from a commercial party related directly or indirectly to the subject of this article.

\section{REFERENCES}

Constant CR, Murley AHG. A clinical method of functional assessment of the shoulder. Clin Orthop 1987; 214:160-4

Fairbank T. Dysplasia epiphysialis multiplex. Brit J Surg 1947; 34: 225-32.

Wynne-Davies R, Hall CM, Apley AG. Atlas of skeletal dysplasias. Edinburgh, etc: Churchill Livingstone, 1985:32-5. 